\title{
TAXONOMIC UTRICULARIA NEWS
}

AndREAS FleISCHMANN • Botanische Staatssammlung München • Menzinger Strasse $67 \bullet$ D-80638 Munich•Germany・fleischmann@1rz.uni-muenchen.de

Since my latest update to the account of Utricularia (Fleischmann 2012), a few more taxa have been described, resurrected from synonymy, or ranges of known species have been extended. These are summarized below in chronological order of publication (species accepted by the author of this text in bold, species considered synonyms in regular font), which today brings the total species number of Utricularia to at least 235 (making it the second largest genus of carnivorous plants, only rivalled by the approx. 250 species of Drosera).

Utricularia brachyceras Schltr. (1899)

A species from the Western Cape of South Africa that has been sunken into synonymy of $U$. bisquamata by Taylor $(1964,1989)$ and in earlier treatments of the South African Flora. This single-flowered tiny annual from $U$. section $\mathrm{Cal}$ pidisca is quite different in flower morphology (Fig. 1) however (the most obvious difference, among others, is the lack of a gibbous palate and the singlelobed stigma, see Stephens 1938) and it has been observed by the author on Gifberg and Cederberg in 2006, where it was evident to represent a distinctive species at first sight.

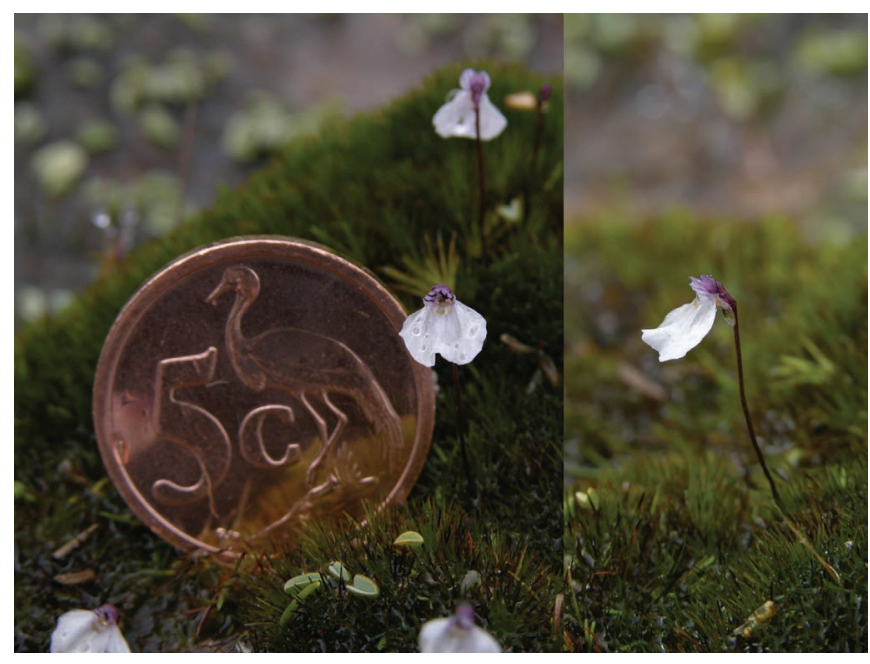

Figure 1: The tiny annual species, Utricularia brachyceras growing at the summit of Gifberg, Western Cape of South Africa. The scapes of this species are always 1-flowered. Note the lack of a gibbose palate and the very short spur of the corolla. For a scale: the 5 Rand cent coin is about $21 \mathrm{~mm}$ in diameter. Photos by Andreas Fleischmann.

Meanwhile, it has been resurrected from synonymy in a new account for the Cape Flora (Manning \& Goldblatt 2012), a decision which is fully supported by the author.

\section{Utricularia linearis Wakabayashi (2010)}

In contrast to my previous treatment, and earlier comments by Allen Lowrie (pers. comms.), where we considered this taxon to represent a mere form of $U$. fistulosa, detailed studies of the plants in habitat now revealed to us that it is indeed a different species, well-separated from the latter by habit, corolla shape, and colour pattern. I agree with Lowrie (2013) to now list this as a distinct 
species of $U$. sect. Pleiochasia from the Northern Territory, Australia, where it seems to be relatively common in some Melaleuca-swamps of the greater Darwin area.

\section{Utricularia corneliana R.W.Jobson (2012) $=U$. reflexa Oliv.}

This aquatic taxon has been described as a new species known from a single swamp in Queensland, Australia (Jobson 2012a), however it morphologically (and phylogenetically, Jobson 2012a) comes very close to the variable and polymorphic U. reflexa, a species widespread throughout tropical Africa and Madagascar (Taylor 1989). Having studied many specimens of U. reflexa both in situ in Africa and in the herbarium, I come to the conclusion that $U$. corneliana easily fits the morphological range of U. reflexa, and that it best should be considered the first record of that species in northern Australia (nearby: a similar range disjunction is already known for Aldrovanda and $U$. gibba, likewise freely floating aquatics).

\section{Utricularia blackmanii R.W.Jobson (2012)}

This tropical species (named after the collector of the oldest specimens; Jobson 2012b) of the affinity of $U$. dichotoma can immediately be told apart from all but three members of $U$. section Pleiochasia by a hollow tubular scape in combination with multi-flowered inflorescence (U. triflora, $U$. tubulata, and $U$. fistulosa likewise share this character combination, but from these species it can be readily told apart by the very different corolla morphology and leaf shape; all other species of that affinity with hollow peduncles bear solitary flowers). The flowers of $U$. blackmanii resemble those of $U$. dichotoma, but differ in having a palate with five white, transversal ridges (in $U$. dichtoma 2-3(rarely more) ridges are present, these are greenish-yellow, rarely purple). The new species is endemic to northern Queensland, from where it previously has been misidentified as U. dichotoma.

\section{Utricularia jobsonii Lowrie (2013)}

This striking addition to the North Australian endemic group of $U$. section Enskide (which now comprises four species, U. chrysantha, U. fulva, U. simmonsii, and U. jobsonii) resembles U. chrysantha in terms of habit and corolla shape (with a distinctly 4-lobed lower lip), but differs by the completely different colour pattern (having a pinkish-lilac corolla with two large, elliptic yellow or white spots on the palate). This species thus far is only known from a single locality in Queensland, northern Australia. It was named after botanist Richard W. Jobson.

\section{Utricularia julianae Delprete $(2014)=U$. tenuissima Tutin}

This "new species" from French Guiana agrees in all morphological characters with the unique U. tenuissima (the minor corolla differences listed fall within the natural range of that species), and hence is considered a younger synonym (the first for that species). The absolutely inappropriate difference "leaves and stolons lacking" (in flowering specimens) has been misused rather frequently in the genus Utricularia to separate dubious taxa. Almost all known species of terrestrial Utricularia can reduce the number of leaves present during anthesis to various degrees (probably depending on nutrition), especially in the annual taxa. Moreover, herbarium specimens often lack leaves as an artifact resulting from collecting the scapes by simply pulling them out of the soil, leaving the inconspicuous, easily detaching stolons and leaves behind in the ground - a fact that has been repeatedly pointed out by Taylor (e.g. 1964, 1989).

U. ameliae R.W.Jobson (2014) = U. dichtoma Labill.

U. barkeri R.W.Jobson (2014) 
U. fenshamii R.W.Jobson (2014) =U. dichtoma Labill.

U. grampiana R.W.Jobson (2014)

These four taxa from south-eastern Australia have been split from the polymorphic U. dichoto$m a$, based on a combination of mainly three morphological characters, namely the relative lengths of transverse ridges on the palate, corolla colour, and shape of the floral bracts. The new species Utricularia barkeri and U. grampiana clearly differ from U. dichotoma (sensu Taylor 1989) by their basiolute floral bracts - in respect to this character they resemble the Western Australian $U$. paulineae, which of course has a quite different corolla shape. Utricularia barkeri and U. grampiana differ from each other mainly by corolla colour and relative length of the ridges on the palate of the corolla lower lip. The new species $U$. ameliae and $U$. fenshamii both would classify as $U$. dichotoma following Taylor's (1989) wider circumscription of that species. Especially the spur shape (a character used to separate $U$. ameliae) is apparently quite variable in this polymorphic species. I hesitate to recognize separate species status for these two yet, and still agree with Taylor's classification here, but Jobson announced a detailed molecular study of the $U$. dichotoma-complex, which hopefully will shed more light on this affinity and the morphological plasticity of some species soon.

\section{Utricularia lowriei}

\section{R.W.Jobson (2014)}

A fifth member of the amazing group of "antenniferous" species with almost insect-like flowers from northern Australia (Fig. 2). These species of $U$. section Pleiochasia have long, antennaelike appendages on their otherwise minute flowers - in combination with a short, sack-like spur and flesh-coloured corollas certainly an adaptation to a common pollinator syndrome (perhaps sexual mimicry). Utricularia lowriei differs from the other members of that group by its corolla lower lip divided into three lobes, the outer two forming the upright-facing long antennae, but the inner one being further divided into three downward-facing, filiform seg-

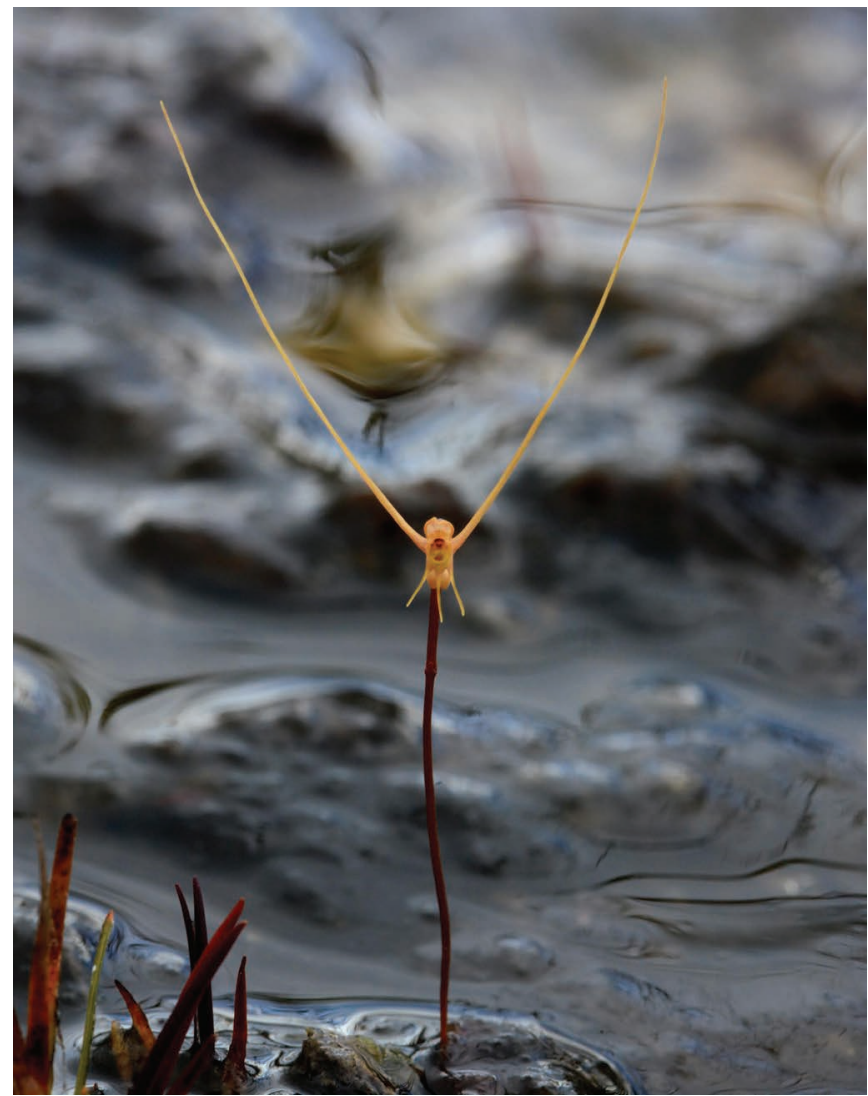

Figure 2: The insect-like flower of Utricularia lowriei, growing in the Sanamere Lagoon area, Queensland, Australia. The entire flower is only about $12 \mathrm{~mm}$ long, including the long antennae. Photo by Richard Nunn. 
ments that exceed the spur in length (hence it has the appearance of $U$. dunstaniae with a "beard"). Needless to mention that it was named in honour of Allen Lowrie, renowned Australian botanist and carnivorous plant expert.

\section{New records:}

Utricularia tenuissima was newly recorded from French Guiana (as "U. julianae"; Delprete 2014), U. reflexa for Queensland (as "U. corneliana"; Jobson 2012a), making it the first record of that species in Australia. Utricularia costata has been discovered at Natal, coastal Rio Grande do Norte state of north-eastern Brazil by carnivorous plant enthusiast Gabriel Santos (http:/www.carnivoras.com.br/lagoas-de-natal-t3529-70.html; last accessed 8 Dec. 2014). So far the species was only known from a disjunct range in Bolívar state of southern Venezuela, and from Roraima, Pará, and Mato Grosso states of Brazil (Taylor 1989), but it seems to be much more widespread and is possibly often overlooked due to its small size (see e.g. records from Goiás state, F. Rivadavia, pers. comms.). The range of the rarely found annual aquatic $U$. warmingii (thus far known from Venezuela, Bolivia, and from the vast floodplains of the Pantanal, Brazil; Taylor 1989) also can be extended, as a population was recently discovered near the town of Yopal, department of Casanare, Colombia, at lowland site at the foothills of the Andes (P. Gonella and F. Rivadavia, pers. comms.) - the closest known localities of the species are situated $c a .350 \mathrm{~km}$ to the north-east in Apure state, Venezuela.

Acknowledgements: I want to thank Fernando Rivadavia, Allen Lowrie, and Jan Schlauer for numerous taxonomic discussions, and for common field trips, and Paulo Gonella for pointing out the online photographs of $U$. warmingii from Colombia to me.

\section{References}

Delprete, P.G. 2014. Utricularia julianae (Lentibulariaceae), a new species from the savannas of the Oyapock River, French Guiana. Phytotaxa 156: 74-78.

Fleischmann, A. 2012. The new Utricularia species described since Peter Taylor's monograph. Carnivorous Plant Newsletter 41: 67-76.

Jobson, R.W. 2012a. Utricularia corneliana R.W.Jobson (Lentibulariaceae), a new species from North Kennedy district of Queensland. Austrobaileya 8: 601-607.

Jobson, R.W. 2012b. A new species of Utricularia (Lentibulariaceae) from northern Queensland, Australia. Telopea 14: 49-57.

Jobson, R.W. 2014. Five new species of Utricularia (Lentibulariaceae) from Australia. Telopea 15: 127-142.

Lowrie, A. 2013. Magnum Opus, Vol. 3. Redfern Natural History, Dorset. [shipped 2014]

Manning, J.C., and Goldblatt, P. 2012. Plants of the Greater Cape Floristic Region 1: The Core Cape Flora. Strelitzia 29. South African National Biodiversity Institute, Pretoria.

Schlechter, R. 1899. Plantae Schlechterianae novae vel minus cognitae describuntur. II. Botanische Jahrbücher für Systematik 27(1-2): 86-220. [Lentibulariaceae: p. 190-191].

Stephens, E.L. 1938. Notes on three South African terrestrial Utriculariae. Journal of South African Botany 4(49): 47-51.

Taylor, P. 1964. The genus Utricularia L. (Lentibulariaceae) in Africa (South of the Sahara) and Madagascar. Kew Bulletin 18: 1-245.

Taylor, P. 1989. The genus Utricularia: a taxonomic monograph. Kew Botanic Gardens, London. Wakabayashi, H. 2010. Utricularia linearis (Lentibulariaceae), a new species from Howard Springs, Northern Territory, Australia. Journal of Insectivorous Plant Society 61: 88-92. 